\title{
Mediation as Problem-Solving Scene in the Light of PTC
}

\author{
KOME - An International Journal of Pure \\ Communication Inquiry \\ Volume 2 Issue 1 p. 3-13 \\ (C) The Author(s) 2014 \\ Reprints and Permission: \\ kome@komejournal.com \\ Published by the Hungarian Communication
}

Studies Assoiciation

\author{
Viktor Németh \\ Corvinus University of Budapest, Hungary
}

\begin{abstract}
Mediation does not only mean a specific procedure or protocol but the related attitude, mindset as well. This perspective gives opportunity to demonstrate the problem in a different way than previously. In the present study the participatory theory of communication (PTC) appears as a framework which makes the communication of participants of the mediation interpretable and transparent.
\end{abstract}

Keywords: mediation, participation, scene, problem solving, conflict resolution

\section{Approaches to the Problem}

From amongst the problem-solving protocols - and the related approaches - the ones related to interpersonal problem-solving can be considered as the most complicated ones because the human thinking could not been fully formalized even over yearthousands.

In the western world, the theories related to problem-solving - along which later on the legal system also crystallizes - is related to the Big Three in Greek Philosophy. ${ }^{1}$ The essence of this philosophy is the analysis - judgement - reasoning - criticism ridge. According to this system, we get around in the world if we try to condense new experience into the boxes, theories deriving from the past. Everything existing either is or is not in a box. The tight logical system based on the duality of ,is" and „is not” and the exclusion of controversy stems from this. (Bono 1995) This is functional in every case when the circumstances existing at time $\mathrm{T} 1$ are identical to $\mathrm{T} 2,3 . . . \mathrm{n}$ timeline, since in this case the past and the future do not vary thus the existing circumstances do not vary either in each world condition (W1,2,3...n). This system builds on the analysis and finding of causation, signification, etc. relationships. It does not take into consideration the possibility that the cause may not be found or the cause may not be terminated.

\footnotetext{
${ }^{1}$ Socrates, Plato and Aristotle

Address for Correspondence: Viktor Németh, email: nemeth.viktor[at]communicatio.hu Article received on the 02th Feb, 2014. Article accepted on the 21th April, 2014

Conflict of Interest: The author declares no conflict of interest.
} 


\subsection{Legal boxes}

The legal system of today in the European continent bases the logical system of the institution on the above mindset as well. The actors of the legal system - judges, prosecutors, attorneys - use this common language. The institutions are basically searching for the truth ${ }^{2}$ when a problem appears and not the possibility for the best solution thereof. That truth along which it can judge and condemn. But what comes after the judgement? After the imposition and implementation of the sentence, either there is a possibility for the agent to somehow change the outcome of his act on his own or he is unable to do so and uses the same solution method as before. Because the subject of judgement is one of the parties involved in the problem. So, in this system, the solution of the problem is to restore the previous world condition through the prohibition or undermining of one of the agents' act causing the problem. Ergo, one of the parties is the cause of the unwanted condition, thus the possible outcome of the participating agents can be described along the winner-loser theory if they are in the legal system with their problem.

\subsection{The problem as possibility}

In a system where the problem is approached as a system of possibilities (Bono 1995), different dates can be related to - previously eventually non-existing - different world conditions. The problem between the agents indicates the need for change or modification. It acknowledges the conditions changed compared to the past and does not want to restore them. It intends to reactivate - in a different way stemming from the nature of change - the induced congestion or modification. Emphasis is put on the different way, namely this approach considers the change and the related possibilities, the new and unknown variables, as natural. It also takes into consideration the change of the date related to the given world condition, namely a new moment in time (future) cannot necessarily linked to an argument related to an already existing past or present moment. This is one of the essential differences between the two approaches.

The other difference is that the agents become the subject of the process in the legal system, examining that which one of them has made a mistake and has deviated from the rules of the legal system.

However, the agents involved at the time of the developing of the problem continue to be present later and in the solution of it as well.

If the parties given the chance to decide on their own future situation, they compare to each other and form their position appropriate to their needs thus enabling a possible win-win outcome (Zagare 1984).

However, this result can only be achieved in the full atmosphere of trust, entirely revealing own interests and needs. The cases analysed and practical experience show that they are able to do so only under certain conditions, namely relevant manifestation of an agent's world for another agent can only be realised under certain conditions. Which means that manifestation of their own world (Horányi 2007) is mutual among the participants, furthermore, it can be detected and interpreted for the parties in - nearly - the same way. To achieve this, one of the most appropriate scenes is mediation.

\footnotetext{
${ }^{2}$ The truth here means the compliance with one of the conditions of the legal system.
} 


\section{Mediation}

Mediation occurs when the participants settle their dispute jointly, voluntarily via involving a neutral and impartial third party (a mediator).

\subsection{Mediation scene}

Mediation scene is a scene where the participants have not been present yet - or at least not with the same partners. Thus, in this space - beyond the current rules of mediation (Bush Folger 2005) - the mediator is able to guide the participants without previously expected behavioural pattern control. One of the mediator's primary tasks is to achieve that the agents participating in the process make their thoughts, feelings and views stored in their own world regarding the given conflict best available for the other participants - with as little modification as possible - thus showing their real needs, interests in a way formed and desired by the agent.

This physical space starts with the formation of appropriately discrete and relaxed atmosphere. In the space furnished by the mediator, the agents have the opportunity to form with the active participation of the mediator - the safe scene appropriate for both their own and the common display of thoughts of challenges and modifications. At the beginning of the mediation session, not only the consciously controllable frames - rules to be obeyed during the session - but also the postural (Scheflen 1964) and proxemics (Hall 1987) dimensions being part of non-verbal communication can be formed freely according to the parties' needs. The most important features of these dimensions are that (1) with the possibility of their manifestation - contrary to e.g. legal scenes ${ }^{3}-$ they supplement the agents' verbal content, increasing the easier interpretation, clarity thereof, (2) they are changing continuously, which can significantly help the dynamics of the parties' continuous communication.

By the possible use of non-verbal communication stemming from the fact that the agents are in a common space, the positive effects of field theories come into operation as well. Kurt Lewin's (Lewin 1972) or the morphogenetic (Sheldrake 2009) field theory may be referred to. When using the common scene, the agents have to be helped to be able to find the optimal use of their non-verbal communication which accounts for $65-70 \%$ of our communication.

\subsection{The role of time in mediation}

The active listening (Gordon 2010) creates a situation of trust in itself, which is indispensable for the manifestation of the own world. If there is not enough time for detection, processing of new information compared to the past - on intellectual and emotional level as well - the agents cannot integrate into their own world the changes necessary to solve the problem.

More time is necessary for widening the viewing options of the parties as in other, ordinary dispute resolution environment - e.g. in a court room. Often the parties realize during mediation time, during the so-called own time how their thoughts were formed and manifested in some missed actions in relation to the case.

It is the mediator's task to create an atmosphere of trust, to which - besides the appropriate communication techniques - it is indispensable to ensure enough time. This is a kind of attunement time which intends to ensure that the participants of the mediation feel a safe, discrete, relaxed environment for the communication.

\footnotetext{
${ }^{3}$ In the continental legal system neither the judge, the prosecutor, the attorney nor the represented parties are characterised by the dynamic enforcement of non-verbal communication, it is much typical in the Anglo-Saxon system. Its use is induced there during the process by the persuasion of the jury consisting of laymen.
} 
Providing the necessary time gives the participants the opportunity to get active listening to disclose their own world. This process can proceed where the necessary conditions are met: (1) agents being able to show the problem; (2) a mediator who guides the process, follows the parties and properly detects their communication; (3) scene providing an adequate level of security; (4) enough time (quantitatively and qualitatively as well).

Significant part of this time is spent on the demonstration of emotions and fears related to the given situation. If enough time is provided to mutually demonstrate the pains related to the past grievances and the fears related to the clearly changing future, the relationship of trust between the agents may be rebuilt - this is the first step to demonstrate the own world related to the creation of the problem. If the relationship is restored on the emotional level, the agents will be able to raise awareness of the problem to be solved and search the possible solutions thereof on this - conscious - scene as well. So, not only the necessary amount of time on the appropriate scene is important but the thematic sequencing assigned to the time unit as well: (1) emotional level, (2) conscious, rational level.

\subsection{The mediator as leader}

This scene is further refined by the mediator ${ }^{4}$ to enable the agents to show, demonstrate their own worlds. By using several verbal and non-verbal techniques, in which it is common that they strengthen the competence, the own and the common resources of the participants. ${ }^{5}$ Bush and Fogel started to use this term in different meaning than earlier in connection with transformative mediation. According to their interpretation - unlike the previous ones - it means capability instead of force equalizing or redistribution. Capability for all participants to become able to make the best possible decision in the given situation. Detection, observation and raising awareness in the parties of own values, strengths and capacities in order to enable them to use their solution toolbars to the fullest. So the agents participating in the conflict use the tools in their own worlds, relevant from the point of view of the solution. When using these skills, the agent participating in problem solving uses the best tools, techniques he/she is holding to demonstrate his/her own world, namely to place it in the common scene.

The main goal of empowerment or confirmation is to transform the information between the agent's own world and their shared world by minimizing the loss. This is true in case of every need related to the conflict, formulating, appearing in the agent. So, the transformer loss stemming from the passage between the two world conditions can be kept below critical level of the lack of understanding. Critical level in my interpretation means the level where information flow between the parties stops or is diverted to a direction different from the internal worlds.

By creating a positive, supporting, safe and discrete communication scene and strengthening the parties' resources, the mediator creates a previously unknown communication situation for the agents. It leads the agents judging the other party negatively, focusing on past events and therefore being in a separate position towards the future joint cooperation and search for solution step-by-step. This guiding can only be realised if during the process the mediator can follow the real-time and content needs of the parties.

\footnotetext{
${ }^{4}$ The mediator is an impartial, unbiased, neutral third party in the system of the transformative mediation analysed here, who does not judge, suggest or decide on the matters related to the mediation. In the types of mediation formed previously, advising or opinion-forming of the mediator was a common practice, e.g. evaluative mediation.

${ }^{5}$ The English literature uses the phrase 'empowerment' for the strengthening of the own resources.
} 
As a result, the agents - the existing in two or more own worlds - mutually understanding each other's own reading create a common own world. The own world jointly created this way contains the preparedness, knowledge and skills of all present and having knowledge regarding the topic. In addition, it contains the desired needs and interests as well, which should be met to terminate the problem for the agent. All of the parties concerned have access to the joint preparedness. (Horányi 2007).

This means the new jointly constructed common own world to enable the involved parties to jointly define that difference/change which caused the conflict between them. To solve the problem specified on the said basis, the agents can use their own or the common resources by completing, coordinating each other.

This can be helped as a first step by the tool of parallel thinking (Bono 1994), the „own time ${ }^{6,}$ " by using a mediation phrase, during which the parties can describe their own views regarding the problem without interruption. This description goes beyond the factual representation, allowing the underlying - real or perceived - feelings, emotions to appear, which hindered the safe demonstration of the own interests, needs. If the agents mutually demonstrated their own readings regarding their own worlds, they mutually have the opportunity for broader insight and understanding, recognition and taking into account of the criteria and thinking of the other party.

In this phase the parties can see the problem from a different perspective, the part of their own "old" world related to the problem changes unintentionally. Thus, on a mental level they get to know something new, something different from their own, however on emotional level the agents also get closer to get to know and understand each other's perspective - that is not equal to immediate and unconditional acceptance. Getting closer is taking place because the agents get to know the thoughts, feelings related to the problem but belonging to each other's own world. Up to now, the agents replaced these thoughts, feelings - skills, knowledge with beliefs based on intentional grounds. The specific approaches shared by the agents eliminate the emotional approach (which is mostly based on fears) related to the problem. After recognition, solely the relevant content part forms basis of the dispute, thus not the other party but the problem to be solved will be focused on.

\subsection{Collective individuals}

The logic of communication of the agents may change as well through the recognition of each other's real demands, needs. Prior to the interaction on the common scene, most of the agents use communication tools, which can be described by 'either-or' logical relations. This mostly arises from the a defensive-offensive view labelling the other party as the cause of problem that is further strengthened by the case-based approach encoded in our problemsolving culture.

When meeting the other agent in the mediation space, the substitution of previous uncertainty, lack of information from the own beliefs is replaced by the necessary access to preparedness. During the first half of the mediation session, the transformation from judgement-based thinking to the system of possibilities approach during the manifestation of the agent's own world. This usually happens with significant emotional impact: crying, trembling, stuttering, shouting, long silence, etc. This transformation means the opening of the gates of the own world. The parties involved in the process, who were present until then

\footnotetext{
${ }^{6}$ The different schools divide the mediation process into 4-7 steps, the second phase is the own time of the agents in every case, where he/she can demonstrate his/her own insights relating to the given conflict from his/her own perspective without the interruption of the others present.
} 
(even) as individual agents ${ }^{7}$ - or they created the impression thereof, or they lived in the belief that they are and will remain such individual agents - will be part of the collective agent category by creating the common own worlds (Ws) and the associated future cooperation. Through creation of the new own worlds such a new system, actions or in other words a pattern is rationalized that are induced for the future by the changes in the past. All of the agents involved consider these changes desirable because usually this new pattern is the maximum which can be sustainably achieved with the least loss by drawing from the joint preparedness of the agents. By the new pattern - which is usually a modification of the old one - the common work carried out undoubtedly overwrites the previous fears and beliefs which were previously built up by the individual agent in his/her own world during the time he/she was separated - on some level - from the other party.

This recovery process established in the mediation also strengthens and promotes the realization of and compliance with the new patterns while making space for a future new option for connection.

\subsection{The own worlds are becoming common}

In the case below, the cooperation of agents in the mediation process can be observed stepby-step:

Couple of years ago a lady with noble ancestors and therefore socialised and living in a matching environment, living in a villa in Buda visited our mediation office. The lady arrived in an upset emotional state. As the owner of more real estates she covered her livelihood and travels abroad from leasing them. The tenant of one of these apartments, Imre disappeared a few months ago and could not been reached since. He even replaced the locks of the front door of the apartment and did not give the owner a new key. The tenant sold the furniture, tools being originally part of the apartment (washing machine, gas stove, television, radio, fridge). Gertrúd initiated the mediation, we contacted Imre, who - as we discussed-was willing to attend a mediation session. However, only Gertrúd was present at the appointed time. The lady showed strong emotional outbursts; she scolded today's youth with increased tone and volume, she expressed the destruction of the old values, her disappointment and feeling of being cheated. After some hesitation, she decided to give a last chance to Imre. Next time, both Imre and Gertrúd were present at the mediation session. Gertrud, as the initiator of the session, explained the extent of damage she suffered and that she feels profound loss of trust against Imre. Imre explained in his own reading that he came to Budapest from the countryside half a year ago for in order to work. In a few weeks he got a job but after a couple of months he -without his fault - lost his job and ran out of his money saved. He was not able to tell Gertrúd that he could not pay because on the countryside where he came from, it is a very big shame for a young vigorous man. Therefore, instead of speaking with her, he ceased communication and replaced the lock. And he sold the furnitures of the apartment per piece in order to have something to eat. When he came to the mediation session, he already had a new job. Gertrúd was surprised to hear that such events can occur in one's life, and to hear that there weren't any friends or relatives living in that village, furthermore the necessity to buy bread

\footnotetext{
${ }^{7}$ The collective agent where a group of agents collectively performs a given act and therefore the act carried out by them has more starting points.
} 
from the price of the stove sold. She saw that Imre sincerely regrets the events and that due to the shame he cannot dare to look at her. Getting to know the real reasons and details, Gertrúd had completely changed. She told Imre ,Why didn't you tell me? We could have spoken about it." During the further parts of the mediation session, they easily agreed on the extent of the damage, the payment method, deadline and instalments thereof and the re-instalment of the original lock.

The realization of the first mediation session was endangered by the thinking, categorization of one of the agents in his/her own world regarding unemployed people - judging, stigmatizing the person itself. If one of the parties accepts and follows this, he/she joins the queue and together with the others - natural persons or the court - destroy further the agent's last possibilites that would allow the solution, improvement, positive change.

On the borderline of this preconception, Imre came to the mediation session - which was the second occasion - when he already had a new job. Based on his explanation, it was a motivation for him and had a positive impact on him that Gertrúd was willing to settle their dispute in the framework of a mediation session. This is the first moment where the positive change in the separate relation may be observed, where the agent detects - often unconsciously - the existence of the other agent as possible partner to solve the problem. The structured information-sharing in the common space, the description of the own world in the common scene totally modified the agent's (Gertrúd's) intention. As Imre had explained his situation in his own reading, the image of Imre, which was previously formed in Gertrúd's mind, completely changed. On the one hand, she did not speak in general (previously she scolded the young people) but she could concentrate on Imre and her own relation to him as she got proper relevant information regarding the events. On the other hand, the facts and information shared from Imre's own world had an emotional impact on Gertrúd. One of the alleged member of the 'delinquent youth' based on the unknown and intentional basis became a specific person with an own, individual life for Gertrúd. Who, compared to her previous experience - she did not have experience based on real facts with regard to young male tenants coming to Budapest from the countryside - changed, filled the place of presumptions, the relevant thoughts in her own world with specific experience.

The net effect of this was that Gertrúd realised that the theft of furniture was not an act against her personally but against the landlord of the apartment because at that moment Imre could cover his needs only from selling the furniture.

Mediation experience show that if the parties get to know the real motivation, they calm down, the fear eliminates resulting in that the rational thinking gradually takes the place of the emotional approach. They start to find the solutions, protocols to be used jointly in the future. By thinking rationally of the extent of claim for damages, both Imre and Gertrúd said the same amount of money. Gertrúd accepted the solution of payment in instalments because she knew that Imre lives from month to month, he has no money saved and there is nobody from whom he could borrow.

\subsection{Community mediation}

So far the cases with small number of participants and the relations between them during mediation were examined. The number of parties involved - based on own experience - may reach 40-50 people as well, the result of the mediation - also based on practical experience may affect a city with thirty something thousand inhabitants. Such a big number of participants practically seems to be unthinkable and impossible to deal with even in terms of 
the time available. How is it possible to demonstrate so many own worlds during such short time?

Nevertheless, the community mediation can be divided into two main groups: (1) the goal is to solve a given problem having the same meaning for every participant from the beginning such as e.g. changing a city's traffic order; (2) restoration of a specific damage, namely supporting, listening to the parties during the offender-victim mediation ${ }^{8}$ or participation of the persons indirectly affected as audience. Such as for example a school fight where the aggrieved party is present as well as the perpetrator or perpetrators and the supporters too who help the parties to reach the best reparation solution. In this case the supporters are the parents, friends, classmates, further actors may be teachers, school psychologist, etc.

Community mediations are also developed to change an existing pattern, habit or to create a system not existing before. However, the interests, needs are completely clear, they are not hidden, or just a very small part of them are. Thus, the community mediation sessions are about the problem statement and searching for solution on a conscious, rational level.

The responsibility of the mediators to properly choose the appropriate representatives of community interests is bigger as in case of other mediations. To properly demonstrate the problem to be solved and articulate the associated needs, demand, it has to be represented on the session by those who have proper knowledge of and access to the preparedness. The identification of and searching for the persons with proper competence, making appointments, etc. requires much time, sometimes even one or two months. However, this ensures the opportunity of community feedback: affected people may appear who previously have not been solicited, either by contacting the organisers on their own iniciatives or on recommendation. There are mediators, who deal with the preparation only, while others usually two persons - deal exclusively with leading the session.

\subsection{Agents in coalition}

During community mediation the agents form a coalition with the other agents involved. The own capacity can be supplemented with capacities made available for each other, which can be used to recognise and solve the problem and during the communication as well (Horányi 2007).

This is exemplified by a community mediation described below which was initiated by the chief architect of the mayor's office of a Hungarian city.

The regulation of the city's traffic system did not follow a unified concept in the past decades. The change in the traffic order consisted of isolated actions of local and occasional problemsolving on an ad hoc basis: making streets one-way, parking order, placement of no stopping and no waiting signs, etc. The specific decisions were not related to each other, they did not form a structure and did not become integral part of the city's traffic order. The decisionmakers did not consult with other parties concerned and competent in the given matter, due to other problems they decided on the traffic order of the city in their own way. This practice has not caused problems for a long time because the single minor decisions did not induce tensions on a community level.

The feature stemming from the geographical situation of the city posseding four different parts - downtown, garden suburb, old town, suburb - has a significant impact on the city's traffic order. This historical separation - clearly appearing on the physical scene as well further strengthened the delay in the appearance of problems related to the traffic order

\footnotetext{
${ }^{8}$ Offender-victim mediation or restorative process is a mediation process where the restoration of some damage takes place.
} 
because the user of every city part felt their own problem as specific and isolated and therefore insignificant for a long time - further delaying the feedback on the actual problem. The user of the different parts of the city - inhabitants, lorry drivers, cyclists, taxi drivers, car drivers, etc. - initially inquired, then complained in the mayor's office one by one but the individual motions have not generated significant changes. Everything the employees of the office could do was limited to listening to and registering the complaint - while they quite clearly understood the majority of the reported problems since they lived in the same city or commuted by car every day. This generated a new problem - strengthening the previous one - because thereby the employees of the office - even those officials who were not working on traffic issues - lost a lot from their professional credibility. Therefore, when they were contacted in other cases, the clients communicated with them on a lower trust level compared to previous cases.

In this situation it was already useless from the employees of the municipality to initiate any consultation, the population did not appear or did not consider the persons initiating these professional fora unbiased. Consequently, an event where the persons concerned - all of the agents who could do something to help the case to move forward - would have been present, could not be realised. They did not consider the municipality officials impartial with regard to the developed problem.

The city's chief architect had previously participated in a municipal mediation process as observer and therefore he already knew the methodology, efficiency, financial and implementation aspects of the procedure. The project was financed by the Ökotárs Foundation, thus the city had to contribute only by providing the location in the building of the town hall twice for four hours.

The mediation session took place on two occasions each lasting for four hours. Three persons were working on the preparation of the mediation for more than two months. During the preparation, the needs of the principal, the leader of the mayor's office (mayor) had been assessed with regard to the end of the mediation:

a) list of the traffic points to be changed,

b) solution proposed to the points,

c) in practice, there was no fund to carry out the changes, therfore only costefficient solution proposals could be taken into consideration.

The decision concerning the location and the possible dates was followed by designation of the city parts concerned and the detection of persons competent in traffic matters and their division into groups per city parts. The persons concerned were contacted via phone, in the course of which we explained to the participants the frameworks, basic rules, goal and duration of the community mediation. We adapted the selection of the participants to the city parts.

Each of the four city parts was represented by:

- assigned transport expert - one person

- representative of the local civil organisation - one person (who previously had collected information in the district)

- local resident - two persons

- expert professionally engaged in transportation being familiar with the city part - one person (e.g. taxi driver, representative of local bus company, traffic policeman)

- representative of the mayor's office - one person

Two mediators led the mediation and the preparatory mediator was present as well as the 
chief architect and his colleague as representatives of the principal. Furthermore, the two representatives of the funding organisations, Ökotárs Foundation were also present as observes. Mediation took place in the assembly hall of the municipality.

On the mediation session, the goal and the formal frameworks of the meeting were described at first, followed by the introduction of the participants. After some formal questions, the proposal of the community was that the persons belonging to the different city parts started to assess, mark and to take notes on the problems regarding the traffic order on one-one map outline sized A0 separately, then when they finished it, they described it in front of the whole community. The mediators have created the groups to represent each type of the above listed agents. The community constructively criticised and supplemented the traffic-related problems collected in respect of each part of the city.

The second session took place two weeks later at the same location with the same participants. The groups worked separately again, this time to solve the problems regarding the traffic order collected at the first session. The first filter of the solutions was the need of the circulating people, the second one was the road traffic regulations - each group had an official expert - and the third one was the low financial opportunities of the city.

The groups made a total of 57 solution proposals, which complied with the road traffic regulations, met the requirements of the experts of the city's traffic department and satisfied the needs of the users of the city, they solved it on a very low budget. Specifically, via the replacement, termination and placement of traffic signs. Significant cost effects had only a blinking yellow traffic light and the painting of two road gateways.

The Traffic Department of the Mayor's Office received the proposals.

The reason of success of the above cases was the coalition on a common scene of more, manifold agents - related to the manifestation of the scene - with knowledge, skills and competence not having met in a common dimension before (Horányi 2007).

The agents with such preparedness - in addition to the proper communication holding them together - actively participated in the workshops relating to the city parts as well as in matters affecting the whole city. The latter one is crucial because the result was not five different solutions of five different city parts but the solution proposals formed by respecting the priorities specified and assigned to the goal at the beginning of the mediation session (compliance with traffic safety, low cost, acceleration of the transport, etc.). Thereby the changes necessary to be implemented for the interest of the whole community - viable transport system in the city - could be detected. The community made the persons in the workshops comply with the priorities set previously both at the time of listing of problems regarding the traffic order - the first mediation session - and at the time of developing the solutions - second session -, namely a strong controller role of the community as a whole could also be observed.

As the result of the knowledge related to the city's traffic order and cooperating in the workshop the listing of all emerged traffic problems and the possibility to change them was made possible. Even at the first meeting, the groups took into consideration opportunities reaching beyond transportation problems, but related to them (e.g. the change in the traffic order should be realised only after arrangement of community spaces). This shows that if the proper preparedness is added up well, they are not only able to solve the problem - namely to solve the problem generated in the past - but to recommend changes proactively in order to continue to find good solutions in the future. This arises from the fact that the own logic of agents participating in the coalition - which was evident in the cost-efficient, constructive thinking in favour of the city - is identical to the logic of other members of the coalition.

During the common work, the parties demonstrated their preparedness from their own world related to the specific problem to be solved on the mediation scene. 


\section{Final thoughts}

The mediation - to be approached even as the alternative protocol of the court procedure or as an approach which is able to open the agents' own world to each other - is a conflict management communication process that currently cannot be replaced by anything else.

The safety, secrecy, dignity and the time of full attention, quality available in the mediation scene provides new opportunities to the agent regarding the communication and problem recognition and/or solution.

Furthermore, it also provides an opportunity to choose from the infinite number of solutions within our reach regarding the future, by respecting our sceptic approaches towards changes but overcoming them.

Because closeness is endless.

\section{References}

Baruch, Robert A. \& Bush, J. P. Folger, 2005. The Promise of Mediation The Transformative Approach to Conflict. San Francisco: Jossey-Bass.

Bono, Edward de 1994. Paralell thinking. London: Viking.

Bono, Edward de 1995. Teach yourself to think, Penguine Books Inc.

Dr. Eörsi Mátyás-dr. Ábrahám Zita(szerk.) 2003. Mediáció: A szelíd konfliktuskezelés, Budapest, Minerva. (Mátyás Eörsi, dr. - Zita Ábrahám, dr. (editors) 2003. Mediation: The gentle conflict management, Budapest, Minerva.)

Gordon, Thomas 2010. : P.e.T. A gyereknevelés aranykönyve [P.E.T. - Parent Effectiveness Training], Budapest: Gordon Kiadó.

Hall, Edward T. 1987. Rejtett dimenziók [The Hidden Dimension], Budapest: Gondolat.

Horányi, Özséb (ed.) 2007. A kommunikáció mint participáció [Communication as participation]. Budapest: Typotex.

Lewin, Kurt 1972. : A mezőelmélet a társadalomtudományban [Field theory in social science], Budapest: Gondolat

Scheflen, Albert E. 1964. The significance of posture in communication systems. Journal for the Study of Interpersonal Processes, 27(4): 316-331.

Sheldrake, Rupert. 2009. Morphic Resonance: The Nature of Formative Causation, Rochester: Park Street Press.

Újlaki, L. 2001. Fogalmi és terminológiai tisztázás igénye a békítés, kiegyeztetés és a közvetítés témakörében [Need for conceptual and terminological clarification in the topic of conciliation and mediation]. Jogtudományi Közlöny (1).

Zagare, Frank C. 1984. Game Theory. Concepts and Applications, London: Sage Publications. 